\title{
UNA FUNDAMENTACIÓN DE LA DEMOCRACIA
}

\author{
Ulises Schmill O. \\ Instituto Tecnológico Autónomo de México (ITAM)
}

A Stanley Paulson

\section{1. Ámbito del presente trabajo}

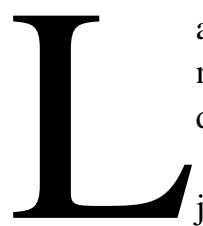

a delimitación de nuestro ámbito de estudio es una tarea preliminar que no debemos evitar. Se trata de establecer la finalidad teórica que perseguimos con este ensayo.

La democracia, como toda institución social, puede ser objeto de las más diversas consideraciones, llevadas a cabo desde perspectivas muy diferentes, determinadas por los intereses del sujeto que haga esas consideraciones. Por lo tanto, la primera distinción que deberemos hacer se encuentra relacionada con el principio de «neutralidad valorativa» de Weber ${ }^{1}$ o su expresión equivalente en la teoría de Kelsen: el principio de la pureza metódica. ${ }^{2}$ Mantendremos con toda pulcritud la distinción entre consideraciones descriptivas o explicativas y consideraciones valorativas y excluiremos de nuestros intereses éstas últimas. En este ensayo no nos proponemos hacer una apología de la democracia o hacer vilipendio de ella, a la manera como los oligarcas griegos criticaban la democracia ateniense como el dominio de la masa, de los muchos, de los pobres, tal como puede leerse en el texto del Viejo Oligarca, atribuido a Jenofonte ${ }^{3}$, o en los textos de Platón y Aristóteles. ${ }^{4}$

De manera análoga, con base en la diferenciación entre el estudio dogmático de una pluralidad de normas y el análisis de los hechos reales históricamente determinables de su aplicación, las siguientes líneas se apartarán de hacer descripciones de la forma en que las instituciones democráticas, vigentes en un Estado determinado, en un tiempo y lugar concretos, han sido aplicadas. No haremos reflexiones y análisis que pertenezcan a la jurisprudencia dogmática ni explicaciones causales sociológicas de la apli-

\footnotetext{
${ }^{1}$ Cf. Weber CV( pp. 221 y ss).

${ }^{2}$ Cf. Kelsen (TGE. p. VIII. PTL1. p. 7; PTL2. p. 1).

${ }^{3}$ Xenophon (CA. p. 37); Cf. Ober (PDDA. pp. 17, y ss).

${ }^{4}$ Ober (PDDA. Cap 4 y 6).
} 
cación de las normas positivas de un Estado que establecen una constitución democrática.

Frente a una pluralidad de normas se puede asumir una postura teórica reconstructiva, que tiene dimensiones explicativas. Se trata de comprender el contenido de las normas positivas que constituyen una institución determinada, haciendo explícitos los conceptos presupuestos, no formulados normativamente, que determinan esos contenidos normativos como un todo pleno de significado. Nos referimos a la «ideología» ${ }^{5}$ que se encuentra en la base de muchas instituciones y que permite la comprensión unitaria de sus contenidos. Estas bases ideológicas serán usadas para comprender el contenido de la institución jurídica de la que nos ocuparemos en este trabajo, la democracia, y no serán usadas para justificarla. Es posible describir con objetividad estas ideas subyacentes, estas «ideologías», sin tomar una posición valorativa. Se trata de establecer las ideas subyacentes que permiten la comprensión como un todo significativo de la institución de la democracia como forma de Estado.

\section{Teoría de la identidad del Derecho y el Estado}

Con las teorías de Weber ${ }^{6}$ y Jellinek ${ }^{7}$ estaba preparado el camino para que Kelsen formulara su teoría de la identidad del Derecho y del Estado. Esta teoría no debe entenderse en el sentido de que el Derecho, como conjunto de mandatos o normas obligatorias y el Estado, como poder o cuadro coactivo que tiene su propio orden, son uno y el mismo objeto, porque ello conduciría a la identificación de dos objetos, que de antemano se han considerado como distintos. Si el Estado es el poder de un cuadro coactivo que garantiza la obligatoriedad del conjunto de normas constitutivas del Derecho, la tesis de la identidad de ambos es imposible y contradictoria, pues se ha partido del supuesto de que el Derecho y el Estado son dos objetos distintos y dos objetos distintos no pueden ser idénticos.

El concepto que se tenga del Derecho determina la aceptación o el rechazo de la teoría de la identidad del Derecho y del Estado. Toda teoría sobre el Derecho que excluya de su concepto la nota esencial de la coactividad, se cierra de antemano la posibilidad de aceptarla. Hay una larga tradición jurídica que concibe al Derecho positivo relacionándolo con el concepto de la coacción. Ihering dice que la coacción del Estado es el criterio absoluto del Derecho, aunque la considera como «un elemento exterior al

\footnotetext{
${ }^{5}$ Ober (MEDA. pp. 38-40).

${ }^{6}$ Weber (ES. pp. 39 y ss )

${ }^{7}$ Jellinek (TGEJ. pp. 130-147).
} 
Derecho». ${ }^{8}$ En esta afirmación se encuentra consignada la tesis de que el Derecho sólo puede ser concebido con el concepto de coacción, acercándose de manera muy estrecha a las concepciones de Weber y Jellinek. El Derecho y el Estado se implican, se relacionan de manera esencial: la coacción del Estado permite definir a la norma jurídica, pero es un «elemento exterior» al Derecho.

En contraposición parcial, Kelsen, desde su primera obra, Problemas $\mathrm{Ca}$ pitales de la Teoría Jurídica del Estado, Desarrollados con Base en la Doctrina de la Proposición Jurídica ${ }^{9}$, presenta de manera enfática la hipótesis fundamental: la norma entendida como un enunciado hipotético, que dispone el ejercicio de la coacción por los órganos del Estado. El Derecho, en resumen, es entendido como un orden coactivo de la conducta humana. Kelsen lleva a cabo un cambio fundamental: en vez de concebir a la coacción estatal como un elemento externo al Derecho, la concibe como parte integrante de la norma jurídica. Esto es posible porque su teoría es el resultado de haber realizado un procedimiento intelectual que he denominado interiorización de la coacción en la norma jurídica. Esta interiorización tiene que producir un cambio fundamental en la concepción de la forma de la norma jurídica: la norma no es concebida como un imperativo, como una regla que prescribe una determinada conducta, a la manera como lo hacen las normas del Decálogo: ¡Haz X!, ¡No hagas Y! Si la coacción se introduce dentro de la norma de manera que ésta dispone el ejercicio condicionado de la voluntad coactiva del Estado, es claro que su forma debe tener carácter hipotético o condicional: sólo bajo ciertas condiciones o supuestos deben ejercerse, como consecuencia, actos coactivos de unos hombres contra otros hombres. Carece de sentido un imperativo cuyo contenido fuera el ejercicio de la coacción. Su formulación sería así: « ¿Coacciona!», lo que, en rigor, es totalmente inadecuado, pues está ordenando el ejercicio de la coacción en todo caso. La coacción, determinante del concepto del Derecho, deja de ser un elemento que se encuentra fuera del contenido de la norma, como un elemento social o natural o psíquico o de cualquier carácter que se quiera. En esto se encuentra la diferencia fundamental entre Kelsen y todos los demás autores que hablan de la coacción estatal. Con esto, toda la problemática sobre la coacción y el monopolio de la fuerza y la violencia ${ }^{10}$ se ha transformado pues, en vez de concebirlas causalmente y como elementos naturales externos al Derecho que garantizan su cumplimiento, adquiere carácter normativo y pierde esa dimensión socio-

\footnotetext{
${ }^{8}$ Ihering (FED. pp. 159-160).

${ }^{9}$ Cf. Kelsen (HP).

${ }^{10}$ Weber (PV. p. 83).
} 
lógica naturalista. El Derecho no es sólo un conjunto de normas que imponen obligaciones, con la garantía externa de un cuadro coactivo, sino un conjunto de normas que facultan al cuadro administrativo para imponer sanciones, incluso coactivamente ${ }^{11}$, a otros sujetos, los cuales son o están obligados por las normas jurídicas precisamente por ser el objeto de actos de coacción. Estar obligado y ser objeto de un acto de coacción ordenado condicionalmente por una norma, son expresiones sinónimas. El llamado «acto antijurídico» debe, entonces, formar parte integrante de la norma, debe ser un elemento integrante del contenido del Derecho, pues constituye la condición o supuesto de la sanción. Con ello, el delito pierde su característica de ser algo ajeno al Derecho, algo que lo ataca o intenta destruir, algo anómico, para convertirse en el supuesto del acto coactivo estatal, pues éste se ejerce contra el sujeto o sujetos que realizaron el acto que aparece como condición de la norma.

Podemos sacar de modo inmediato la siguiente conclusión: si el Estado es un cuadro coactivo y el Derecho es un orden coactivo, y tomando en cuenta que el cuadro coactivo del Estado posee un orden con base en el cual es posible hacer la imputación de ciertos actos a su unidad, ergo el Estado es idéntico al Derecho.

Una consecuencia inmediata de lo anterior es que todos los problemas relacionados con el Estado, en la concepción tradicional, al quedar incorporados en la norma jurídica, se han convertido en problemas normativos y el Estado es concebido como el mismo orden jurídico. ${ }^{12}$

La identidad del Derecho y del Estado significa, en el fondo, que todo problema referente al Estado es un problema jurídico y debe resolverse en función de las normas jurídicas. Este es el sentido teórico de la teoría de la identidad del Derecho y del Estado. ${ }^{13}$

\section{Teoría jurídica de las formas de Estado}

Jellinek había observado que las divisiones de las formas de Estado que se han propuesto en el curso de la historia no tenían en cuenta el «elemento peculiar» del Estado que lo distingue de todas las demás formaciones sociales: el poder. ${ }^{14}$ Jellinek considera que el criterio que debe ser utilizado para determinar las formas del Estado sólo puede hallarse en el «fundamento

${ }^{11}$ Kelsen (TGE. p. 62): «Si el Derecho es un orden coactivo, cada norma jurídica habrá que prescribir y regular el ejercicio de la coacción. Su esencia tradúcese en una proposición, en la cual se enlaza un acto coactivo, como consecuencia jurídica, a un determinado supuesto de hecho o condición»

${ }^{12}$ Cf. Kelsen (SJS); Kelsen (CTGE. p. 116-7).

${ }_{13}$ Kelsen (CTGE. pp. 131-2).

${ }^{14}$ Jellinek (TGEJ. p. 538). Para mostrar la falta de un criterio sistemático para clasificar las formas del Estado, expone las siguientes clasificaciones: «Algunos ejemplos darán una idea del subjetivismo y confusión que reina en esta materia: despotismo, teocracia, Estado de dere- 
de las relaciones constantes de voluntad que alcanzan en él su expresión». ${ }^{15}$ Esto significa, en terminología más moderna, la forma como se ejerce el poder dentro del Estado, lo que se manifiesta en una división jurídica sobre «el modo de formación de la voluntad del Estado». ${ }^{16}$ Con esto orienta su proceder teórico por un camino correcto, con base en la brújula del Derecho, a la que por cierto desconoce cuando hace la aplicación correspondiente, pues considera que puede clasificarse a los Estado conforme la Constitución establezca la formación de la voluntad estatal «mediante un proceso psicológico, esto es, natural, o por un proceso jurídico, esto es, artificial». ${ }^{17}$

Si la teoría del Estado es teoría jurídica, en el sentido de que todos los problemas relativos al Estado deben plantearse y resolverse primeramente de manera normativa, entonces la determinación de las formas del Estado debe ser planteada y resuelta con base en el Derecho positivo. ¿Cuál es el criterio jurídico que nos permite tipificar las diferentes formas del Estado? Preguntamos por el principio con arreglo al cual las formas estatales pueden ser tipificadas. Ya desde la antigüedad se utiliza el criterio del número de personas que se encargan de la creación del orden estatal y de las cualificaciones para ejercer esas funciones.

\section{Determinación formal de la democracia y la autocracia}

La democracia y la autocracia como formas del Estado pueden concebirse de manera puramente formal, haciendo referencia a los conceptos derivados de una concepción dinámica del Derecho. En esta determinación de carácter formal, es necesario enfatizarlo, no interviene elemento ideológico, deóntico o valorativo alguno. Es neutral en relación con cualquier clase de valor, estimativa o preferencia. Por ello, es puramente descriptiva y operacional: el concepto determina cuáles son las notas que poseen los objetos a

cho (Welcker); repúblicas, autocracias, despotismo (Heeren); Estados orgánicos y mecánicos; y entre los primeros, Estados nómadas y agricolas; entre los últimos, jerarquías e ideocracias, regímenes militaristas, plutocracias (Leo); Estados idólatras, individualistas, de razas, formales (Rohmer); particulares, patrimoniales, Estado antiguo, Estado de Derecho en la época moderna $(M o h l)$; soberanía de uno, que se divide en monarquías y repúblicas monocráticas y pleonocráticas (Gareis). En el libro de Schwarcz, Elemente der Politik, pág. 79 y sigs., se hallarán infinidad de divisiones de la literatura moderna, según las distintas direcciones: aristocracias, timocracias, democracias puras, democracias de cultura y formas mixtas; dominaciones hereditarias y Estados libres; Estado policía y Estado de derecho; Estados centralizados y Estados organizados tomando por base el selg-goverment; Estados que descansan sobre la autonomía provincial y municipal, y formas mixtas; Estados con una sola lengua, con varias; territoriales, nacionales y de nacionalidades; Estados homodoxas y polidoxas, en infinidad de otras subdivisiones». (Ibidem)

${ }^{15}$ Jellinek (TGEJ. p. 539).

${ }^{16}$ Jellinek (TGEJ. p. 540).

${ }^{17}$ Ibídem. 
los que se les califica de democráticos o autocráticos, sin pretender justificarlos. Es una especie de geometría social. Estos conceptos formales son insatisfactorios emotiva y conceptualmente. Los hombres demandan más de un concepto social, sobre todo cuando su vida y sus intereses más preciosos se encuentran sujetos a los órdenes sociales o estatales a los que se refieren esos conceptos formales. De la descripción queremos pasar a la explicación, o mejor, a la reconstrucción conceptual. Si hay peste en Tebas, entonces se demanda que el oráculo dé la explicación de los sufrimientos del pueblo tebano. Esta explicación pueden proporcionarla los dos conceptos de «libertad», entendido como libertad política, y de «igualdad», como lo veremos en el apartado siguiente.

Para darnos a entender con mayor pulcritud y con objeto de tener un esquema de lo que se dice, quiero representar el acto de creación de una norma de la siguiente manera, que es la más simple posible:

(NP) a(n) Norma positiva

Como todo acto, el de creación de una norma se lleva a cabo por un sujeto $(\mathrm{p})$, tiene un cierto contenido o significado $(\mathrm{m})$, y acontece en un tiempo específico ( $\mathrm{t}$ ) y en un espacio determinado (e). Si incorporamos en nuestro esquema estas dimensiones de realización del acto de creación de una norma, tenemos

(DR) a(p, m(=n), t, e) Dimensiones del acto normativo

La dimensión material $\mathrm{m}$ de un acto de emisión de una norma, i.e., el sentido del acto de habla de emisión de una norma o mandato, es el contenido de la misma, como significación ideal. Esto explica que la dimensión de realización material $\mathrm{m}$ del acto de creación normativa sea la misma norma.

Cuando las dimensiones de realización de un acto normativo están determinadas en una norma, reciben el nombre de ámbitos de validez de la norma. Por lo tanto, toda norma al regular la conducta humana determina las dimensiones de realización de ésta, i.e.,

(AV) $\mathrm{n}(\mathrm{p}, \mathrm{m}, \mathrm{t}, \mathrm{e})$ Ámbitos de validez normativa

Una pluralidad de normas que forman un orden $\mathbf{O} \mathbf{N}^{18}$ se describen indicando cuáles son sus ámbitos de validez normativa.

La democracia, desde un punto de vista formal, puede caracterizarse si se relacionan las dimensiones de realización de los actos creadores de un orden normativo $\mathbf{O N}$ con los ámbitos de validez de este propio orden norma-

${ }^{18}$ Por el momento prescindimos de analizar la estructura interna de este orden normativo ON. Puede estar constituido por una norma o por una pluralidad de normas, del mismo o de diferente grado. 
tivo, en especial por lo que respecta al ámbito personal de validez. Formalmente hablando, democrático es aquel orden normativo en el que existe identidad de los sujetos creadores del orden normativo y los sujetos sobre los cuales es válido dicho orden. Aquí el concepto determinante es el de la identidad entre los sujetos creadores y los sujetos sometidos al orden (o lo que es lo mismo, los sujetos para los cuales dicho orden es válido). Es el resultado de relacionar la dimensión personal de realización del acto creador de las normas con el ámbito personal del orden normativo creado. Utilizando los esquemas anteriores, podemos representar este concepto de la siguiente manera:

(D) $a_{i}\left(p^{c}, m\left(=O N\left[p^{s}, m, t, e\right]\right), t, e\right)$ Democracia o autocracia

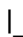

$$
=0 ́ \neq
$$

lo cual significa que los sujetos que llevan a cabo el proceso creador del orden normativo $\mathrm{ON}, \mathrm{p}^{\mathrm{c}}$, son o no son los mismos que los que constituyen el ámbito personal de validez del orden normativo creado por dicho procedimiento (los súbditos), i.e., ps. Es decir, si existe la identidad mencionada, estamos frente a un orden normativo democrático:

$$
\mathrm{p}^{\mathrm{c}}=\mathrm{p}^{\mathrm{s}} \text { ó } \mathbf{I}\left(\mathbf{p}^{\mathbf{c}}, \mathbf{p}^{\mathbf{S}}\right)-\text { democracia. }
$$

En cambio, si tenemos como estructura formal

$$
\mathrm{p}^{\mathrm{c}} \neq \mathrm{p}^{\mathrm{s}} \text { ó } \neg\left(\mathrm{p}^{\mathrm{c}}=\mathrm{p}^{\mathrm{s}}\right) \text { ó } \neg \mathbf{I}\left(\mathbf{p}^{\mathbf{c}}, \mathbf{p}^{\mathbf{S}}\right) \text { - autocracia. }
$$

estamos frente a todas las formas de Estado que no son democráticas, las que podemos denominarlas genéricamente con el nombre de «autocracia», pues en ellas no existe la identidad de los sujetos creadores del orden con los sometidos al mismo, que es la conditio per quam de la democracia, definida formalmente.

De estos principios se dejan derivar todas las formas de Estado, que siempre han tenido como concepto determinante el número de aquellos que ejercen el poder, es decir, de aquellos que llevan a cabo el procedimiento de creación del orden normativo $\mathbf{O N}$.

\section{Democracia directa}

Si la dimensión personal de realización del acto creador de las normas jurídicas es idéntica al ámbito personal de validez del orden normativo creado y si ambos son idénticos al pueblo, i.e., si $\mathrm{p}^{\mathrm{c}}=\mathrm{p}^{\mathrm{s}}$ y s $=$ pueblo, estamos frente a una democracia directa: es el pueblo en su totalidad el que crea las normas integrantes del orden normativo en cuestión. 


$$
\mathrm{a}_{\mathrm{i}}\left(\mathrm{p}^{\mathrm{c}}, \mathrm{m}\left(=\mathrm{ON}\left[\mathrm{p}^{\mathrm{s}}\left(=\text { pueblo }=\mathrm{p}^{\mathrm{c}}\right), \mathrm{m}, \mathrm{t}, \mathrm{e}\right]\right), \mathrm{t}, \mathrm{e}\right)
$$

De la observación de este esquema puede surgir la pregunta de cuál es el fundamento de considerar a ciertos actos, de la multiplicidad de ellos observable, como los creadores del $\mathbf{O N}$, debemos decir que se consideran sólo aquellos cuya ejecución es empíricamente verificable, es decir, de aquellos que, conforme al sentido subjetivo de los mismos, logran que los demás se comporten. La eficacia de un orden normativo $\mathbf{O N}$ es el criterio determinante teóricamente para la identificación de ciertos actos como los constituyentes del orden jurídico de un Estado en particular. La formulación de este criterio en la forma de una norma llevó a Kelsen a postular su «norma fundante básica» $\mathrm{o}$ «norma fundamental hipotética», a la que podemos simbolizar como «nF». Con ello, el anterior esquema se transforma en el siguiente:

$$
\mathrm{nF}\left\{\mathrm{a}_{\mathrm{i}}\left(\mathrm{p}^{\mathrm{c}}, \mathrm{m}\left(=\mathrm{ON}\left[\mathrm{p}^{\mathrm{s}}\left(=\mathrm{p}^{\mathrm{c}}\right), \mathrm{m}, \mathrm{t}, \mathrm{e}\right]\right), \mathrm{t}, \mathrm{e}\right)\right\}
$$

De este último esquema podemos derivar que el orden normativo en cuestión, cuyo grado de democracia se está juzgando, es caracterizado como democrático por la existencia de un conjunto de normas $\mathbf{n F}$ que establecen el proceso de creación de $\mathbf{O N}$ de manera democrática. Este conjunto de normas que establecen la forma de creación democrática del orden en cuestión, son normas que establecen facultades, en la medida que determinan el proceso de creación de $\mathbf{O N}$, en el que los sujetos que ejercen estas facultades son idénticos a los sujetos sometidos al mismo. Este es un tipo ideal. Luego veremos las restricciones que este tipo ideal debe sufrir para acercarse a la descripción de los órdenes normativos reales, determinables históricamente. Lo que debe quedar claro es que esta $\mathbf{n F}$ es solamente la formulación del criterio de la existencia de un orden normativo, mediante la proyección de un modelo de las normas sobre los actos de poder observables.

Es necesario analizar brevemente las distintas votaciones que pueden darse dentro de un cuerpo colegiado que emite una norma, con objeto de establecer el modus operandi de las votaciones y los significados asociados a ellas.

Con la teoría del contrato social se ha estimado que el acto fundatorio del Estado debe realizarse estando de acuerdo la totalidad de la sociedad, es decir, se exige que exista unanimidad de votos aprobatorios en el acto de creación del contrato fundatorio. Esto ya está claro en Rousseau, como veremos posteriormente cuando expongamos la tesis de la libertad como el fundamento de la democracia. El esquema del principio de unanimidad para la creación del orden normativo $\mathbf{O N}$ en cuestión sería el siguiente:

(U) $n F\left\{a_{i}\left(p^{c}(100), m_{(100 \%(+)}\left(=O N\left[p^{s}\left(=p^{c}\right), m, t, e\right]\right), t, e\right)\right\}$ Unanimidad 
La razón por la cual ponemos la votación unánime dentro del ámbito material de validez es porque la unanimidad se refiere a la uniformidad en la aceptación del contenido normativo puesto a discusión: se vota afirmativamente por un cierto contenido. La materia de cada acto recibe un sí en el proceso de votación; por lo tanto, se requiere $100 \%$ de síes, la totalidad de los votos son aprobatorios. Empleando la terminología de Kelsen, la totalidad de los votos tienen el mismo contenido, en el caso, el contenido es aprobatorio de una cierta propuesta por el $100 \%$ de los que participan.

Cuando se exige la unanimidad de votos y existe un sujeto que vota en contra, se presenta la siguiente situación: no hay aprobación del orden normativo $\mathbf{O N}$, es decir, no hay creación de las normas.

(VD) $n F\left\{\mathrm{a}_{\mathrm{i}}\left(\mathrm{p}^{\mathrm{c}}(100), \mathrm{m}_{(99 \%(+)+(1 \%(-)}(\varnothing \mathrm{ON}=Æ), \mathrm{t}, \mathrm{e}\right)\right\}$ Voto del disidente

En el caso de que se requiera para la aprobación de $\mathbf{O N}$ una votación de mayoría calificada, por ejemplo, del $75 \%$, el esquema del mismo sería el siguiente:

(MC) $n F\left\{\mathrm{a}_{\mathrm{i}}\left(\mathrm{p}^{\mathrm{c}}(100), \mathrm{m}_{(\min 75 \%(+)+\max 25 \%(-)}\left(=\mathrm{ON}\left[\mathrm{p}^{\mathrm{s}}\left(=\mathrm{p}^{\mathrm{c}}\right), \mathrm{m}, \mathrm{t}, \mathrm{e}\right]\right), \mathrm{t}, \mathrm{e}\right)\right\}$

En este caso, los sujetos que votan la aprobación del orden normativo en cuestión, $\mathbf{O N}$, se divide en dos grupos: una mayoría del $75 \%$ o mayor y una minoría del $25 \%$ o menor. La mayoría vota a favor de la propuesta normativa y la minoría en contra, lo que está representado por los signos «(+)»y $\ll(-) »$.

La mayoría simple o absoluta tiene el siguiente esquema que se explica por sí mismo:

(MA) $n F\left\{\mathrm{a}_{\mathrm{i}}\left(\mathrm{p}^{\mathrm{c}}(100), \mathrm{m}_{(\min 51 \%(+)+\max 49 \%(-)}\left(=\mathrm{ON}\left[\mathrm{p}^{\mathrm{s}}\left(=\mathrm{p}^{\mathrm{c}}\right), \mathrm{m}, \mathrm{t}, \mathrm{e}\right]\right), \mathrm{t}, \mathrm{e}\right)\right\}$

En el caso de que se considere una mayoría relativa, en el caso de que existan tres proposiciones de creación normativa, su esquema sería el siguiente en el caso más simple:

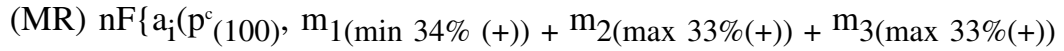
$\left.\left.\left(=\mathrm{ON}\left[\mathrm{p}^{\mathrm{s}}\left(=\mathrm{p}^{\mathrm{c}}\right), \mathrm{m}, \mathrm{t}, \mathrm{e}\right]\right), \mathrm{t}, \mathrm{e}\right)\right\}$ Mayoría relativa

En este caso, no existe una única proposición que ha de ser votada, sino por lo menos tres, en relación con las cuales se divide la votación y se aprueba aquella que obtenga el mayor número de votos. En el esquema está representada la votación mínima del ganador. Es claro que si el ganador obtiene una votación mayor que la mínima, lo hace a costa de cualquiera o ambas de las otras posibilidades.

El ámbito personal de validez de las normas que establecen los actos creadores de Derecho en una democracia, puede encontrarse más o menos 
modalizado, en el sentido de que puede contener cualificaciones especiales para que los sujetos integrantes del pueblo estén facultados para participar en los proceso democráticos. En Grecia sólo los ciudadanos atenienses tenían estas facultades, estando excluidos los esclavos, los extranjeros, los locos, las mujeres y los infantes. Estas modalidades han sido tomadas en cuenta para hacer clasificaciones de las formas de Estado, como tuvimos oportunidad de indicar brevemente más arriba.

\section{Democracia indirecta o representativa}

Hemos presentado la democracia directa en la que los sujetos creadores del ON son los mismos que los sujetos que estarán sometidos al mismo y en la que participa todo el pueblo. Pero en las democracias parlamentarias o representativas, estos esquemas no pueden aplicarse directamente, porque el proceso de creación del orden normativo está dividido por lo menos en dos etapas: una, referida al ámbito personal de validez de las normas que establecen el proceso de creación del $\mathbf{O N}$, i.e., a la elección de los sujetos que realizarán los actos del proceso creador del orden y, otra, al proceso mismo de la creación del conjunto de normas, por ejemplo, el proceso legislativo.

(DR) $n F\left\{\mathrm{a}_{0}\left(\mathrm{p}_{\left(10^{7}\right)}, \mathrm{m}_{(\mathrm{U} \text { v MA v MC v MR })} \rightarrow \mathrm{p}^{\mathrm{c}}(100), \mathrm{t}, \mathrm{e}\right), \mathrm{a}_{\mathrm{i}}\left(\mathrm{p}^{\mathrm{c}}(100), \mathrm{m}_{(51 \%}\right.\right.$ $\left.\left.(+)+49 \%(-)\left(=\mathrm{ON}\left[\mathrm{p}_{\left(10^{\mathrm{s}}\right)}^{8}, \mathrm{~m}, \mathrm{t}, \mathrm{e}\right]\right), \mathrm{t}, \mathrm{e}\right)\right\}$ Democracia representativa

¿Qué significa este esquema? La norma que establece la facultad $\mathbf{n F}$ contiene dos procesos de creación normativa: $\mathrm{a}_{0}(\mathrm{)}) \mathrm{y} \mathrm{a}_{\mathrm{i}}(\mathrm{)}) \mathrm{a}_{0}$ está orientada a la constitución del ámbito personal de validez del procedimiento de creación de $\mathbf{O N}$, es decir, $\mathrm{p}^{\mathrm{c}}$, a la determinación de los sujetos que integran el órgano creador del orden normativo $\mathbf{O N}$, por ej. los titulares del órgano legislativo, es decir, los diputados y los senadores. Se trata del proceso electoral del órgano legislativo, el cual puede tomar cualquiera de las modalidades expuestas más arriba U, MA, MC, ó MR. Como toda facultad prevista en una norma contiene sus ámbitos de validez: p se refiere al conjunto de sujetos, generalmente los ciudadanos que ejercerán esas facultades eligiendo a los sujetos que van a llevar a cabo el proceso de creación del orden normativo en cuestión $\mathbf{O N}$. En el caso, se supone que son en cantidad de $10^{7}$, o sea, 10 millones de electores, los cuales van a elegir a $\mathrm{x}$ número, representado por 100. Todas las cualificaciones jurídico-positivas necesarias para ser ciudadano y para ejercer las facultades electorales están simbolizadas aquí. El ámbito material es el contenido del acto $\mathrm{a}_{0}$, que se refiere a los sujetos que resultarán electos por el ejercicio del derecho político. Es claro que la elección se lleva a cabo en un lugar y en un tiempo determinado, lo que especifica las letras $t$ y e que se encuentran dentro del paréntesis de $a_{0}$. Estamos en presencia de la que constituye la democracia representativa. Las di- 
versas modalidades de la elección de los sujetos que ejercerán las facultades de creación del orden normativo, como el sistema proporcional, se pueden representar aquí.

Las otras formas de Estado se dejan derivar de nuestros esquemas fundamentales, atendiendo tanto a la cualificación de los sujetos que llevan a cabo el proceso de creación del $\mathbf{O N}$, como a la forma de designación de él o ellos.

$\mathrm{nF}\left\{\mathrm{a}_{0}\left(\mathrm{p}_{(\text {herencia, designación, etc.) }}, \mathrm{m} \rightarrow \mathrm{p}^{\mathrm{c}}, \mathrm{t}, \mathrm{e}\right), \mathrm{a}_{\mathrm{i}}\left(\mathrm{p}^{\mathrm{c}}\right.\right.$ (uno o varios con cualificaciones $\left.\left.) \neq \mathrm{p}^{\mathrm{s}}, \mathrm{m}\left(=\mathrm{ON}\left[\mathrm{p}^{\mathrm{s}}, \mathrm{m}, \mathrm{t}, \mathrm{e}\right]\right), \mathrm{t}, \mathrm{e}\right)\right\}$

Esto significa que siempre existe empíricamente un acto de designación o nombramiento o elección a 0 tomando como parámetros para ello cualquier criterio menos la elección popular. El sujeto facultado para crear $\mathbf{O N}$ es uno o varios, los cuales se encuentran específicamente cualificados, en ciertos sentidos, ya sea por sus cualidades de nacimiento, por pertenecer a una clase, etc., i.e., $\in \mu$, donde $\mu$ es una variable para designar esas cualificaciones.

\section{Teoría de la representación ${ }^{19}$}

Debe hacerse una distinción entre el concepto de representación y el concepto de órgano de un orden, pues comúnmente se confunden. La representación supone la existencia de dos sujetos A y B, los cuales tienen la capacidad, jurídica o de otra clase, para realizar un acto determinado y se encuentran en una relación determinada que más adelante especificaremos. En cambio, ser órgano de un orden significa que un sujeto A tiene la facultad de crearlo o ejecutarlo, pero no existe esa peculiar relación entre dos sujetos. Cierto, se acostumbra afirmar que el órgano representa a la persona colectiva constituida por ese orden, pero entonces se está haciendo uso de la ficción de la persona. Expresado lo anterior con las enérgicas palabras de Kelsen, se diría:

La organización (en sentido jurídico-esencial) no es representación, porque ésta es una relación material entre distintos hechos (o entre los hombres que la realizan), mientras que la primera es la relación de un hecho con un orden o sistema de hechos. Es una aplicación radicalmente equivocada de la idea de representación a la relación del Estado con sus órganos, el considerar a aquél como un hombre que, a la manera del niño y del loco, carece de «voluntad» y sólo puede «querer» a través de sus órganos, que son sus «representantes» legales, pues la voluntad del «Estado» es algo esencialmente distinto de la voluntad que un hombre manifiesta al realizar un hecho. ...Sólo la hipóstasis de la unidad personificada del orden jurídico puede llevar a desviaciones tan grotescas. ${ }^{20}$

${ }^{19}$ Para un análisis de los diversos conceptos sobre la representación Cf. Fenichel (CR).

${ }^{20}$ Kelsen (TGE. p. 400). Jellinek afirma que la relación de representación se da entre un órgano primario (en nuestra terminología A) y uno secundario (en nuestra terminología B). Jellinek (TGEJ. p. 478). 
La teoría de la representación de Kelsen es la siguiente:

En virtud de determinación positiva, la voluntad del representante B «vale» como voluntad del representado (A). Pero esto no significa sino que si B realiza el hecho X, éste ha de tener la misma consecuencia (Y) que si lo hubiera realizado A. Si, por ejemplo -para poner un caso de representación legal-, el tutor celebra, en calidad de tal, un contrato, comprometiéndose a ciertas prestaciones, el incumplimiento lleva aparejada la ejecución en el patrimonio del pupilo. Es una abreviación decir que, dentro de esta relación, la voluntad del tutor es voluntad del pupilo. Se parte del siguiente principio general de Derecho: si alguien contrae una obligación contractual por propia voluntad (y ningún contrato es posible si no se trata de una manifestación de voluntad «propia», auténticamente libre), en caso de incumplimiento debe seguirse ejecución en su patrimonio (esto es, en el del que realizó el contrato). Aplicando los signos convencionales anteriores, la fórmula de este principio es como sigue: si A realiza el hecho X, debe aplicarse la consecuencia Y; y el contenido de esta consecuencia se dirige contra A. Pero esta regla tiene excepciones. Hay casos en que la manifestación de voluntad de otro tiene las mismas consecuencias que la propia. Para la exposición, es más fácil no formular este caso excepcional como regla autónoma, y no señalar expresamente las consecuencias. Se dice: si B realiza el hecho X, se aplican las mismas consecuencias que si lo hubiera realizado A. En el caso de que $\mathrm{B}$ realiza el hecho $\mathrm{X}$, se remite -para las consecuencias- al caso de que ese hecho sea realizado por $\mathrm{A}$, porque se considera que la regla del segundo caso es limitación de la del primero, que es la regla fundamental y capital. ${ }^{21}$

El siguiente esquema expresa esta teoría:

\section{(R) Si $A(X) \rightarrow Y / A$; si $B(X) \rightarrow Y / A$, entonces $B$ es representante de $A$.}

La exposición es muy clara. La representación es la relación entre dos hechos distintos, relacionados de manera específica. Las mismas consecuencias jurídicas en contra del patrimonio de A se realizan o deben realizarse para el caso en que realice $\mathrm{A}$ la conducta $\mathrm{X}$, pero también para el caso en que la realice $\mathrm{B}$, i.e., $\mathrm{A}(\mathrm{X}) \mathrm{v} \mathrm{B}(\mathrm{X})$ àY/A. Si esto es establecido contractualmente estamos frente al negocio jurídico del mandato. Si está establecido legalmente, sin que intervenga la voluntad de A, estamos en presencia de la representación legal.

En principio, el sujeto A está en posibilidad jurídica de llevar a cabo o realizar el hecho $\mathbf{X}$ que tiene la consecuencia Y/A. No siempre es esto posible y la representación, o mejor, el modelo de la relación de representación se extiende a casos en los cuales se considera que ciertas personas no pueden llevar a cabo, por circunstancias especiales, los hechos que son el supuesto de estas relaciones, es decir, hay sujetos o personas que no se encuentran en capacidad de llevar a cabo la manifestación de voluntad que constituye el supuesto de la creación del contrato y sus consecuencias. Es-

\footnotetext{
${ }^{21}$ Kelsen (TGE. p. 398).
} 
ta relación de representación se encuentra relacionada con el concepto de responsabilidad, relación que no explicaremos en este lugar. En este caso, se dice que el sujeto representado sólo quiere por conducto de su representante, que manifiesta su voluntad a través de sus representantes. A los sujetos jurídicos, a las personas que carecen de voluntad psicológica generalmente se les da un representante, para que por conducto de éste manifiesten su voluntad. Claramente aquí puede percibirse una ficción. Lo que acontece es que el representado no está en capacidad de realizar $\mathbf{X}$, es decir, no se da ni puede darse el caso $\mathbf{A}(\mathbf{X})$, porque el sujeto $\mathbf{A}$, por ser menor de edad o loco, no tiene la capacidad de manifestar su voluntad para obligarse. Se dice que $\mathbf{B}$ es su representante, por ser el único que puede manifestar su voluntad, que no vale como propia, sino como del representado, puesto que las consecuencias del incumplimiento recaen sobre el patrimonio de éste y no de aquél. El esquema sería:

\section{Si $\neg A(X)$ y $B(X)$, entonces $Y / A$}

En este esquema, $\mathbf{A}(\mathbf{X})$ no puede realizarse, aunque podría llegar a realizarse, por ser una persona, y $\mathbf{B}(\mathbf{X})$ se presenta de manera que tendría la misma consecuencia que lo hubiera realizado $\mathbf{A}$, entonces hay una relación de representación legal, no convencional. Podría decirse que A responde por la conducta de $\mathbf{B}$, su representante. Como esto va en contra de los sentimientos jurídicos normales se atenúa este disgusto diciendo que $\mathbf{A}$ ha querido por conducto o a través de su representante. Subyace el concepto de que A por ser persona podría querer, tiene la posibilidad abstracta de querer. Si esta posibilidad abstracta se simboliza con el signo de la posibilidad (M), entonces podríamos escribir

\section{$S i \neg A(X)$ y $M A(X)$ y $B(X)$, entonces $Y / A$}

Con ello, se acallan los inconvenientes de situaciones tan contrarias a nuestro sentimiento de conveniencia práctica y de diversa otra índole, como criterios de justicia, pues en principio choca con estos criterios que un incapaz sea responsable por los actos de su representante.

Si el sujeto A por sus características no puede jurídicamente, en ningún caso, realizar el hecho $\mathbf{A}(\mathbf{X})$, pero sin embargo se quiere poder imputarle las consecuencias al mismo, lo más cómodo es aplicar el concepto de la relación de representación y decir que aunque no puede querer, lo hace por conducto de su representante. Así se ha formado la idea de que el Parlamento es el representante del pueblo. En realidad, el pueblo no está jurídicamente capacitado para ejercitar la facultad legislativa, pues el proceso de creación de las leyes sólo lo puede realizar el conjunto de personas que integran al Parlamento. La afirmación de que el pueblo es el legislador, que tiene la fa- 
cultad de legislar, es simplemente falsa, pues conforme a las constituciones modernas, sólo otorgan esa facultad a las personas que han sido electas por medio de los sufragios de las personas con el Derecho para hacerlo. Habría representación del pueblo por el Parlamento

...que la voluntad del Parlamento es la voluntad del pueblo, y que éste no puede querer sino a través de aquél...(sería esta afirmación justificada sólo) si existiese una regla positiva de Derecho que diera a todas las decisiones del «pueblo» el carácter de leyes, y sólo por excepción pudiera el parlamento adoptar resoluciones con la misma eficacia que si hubiesen sido adoptadas por el pueblo. Esto ocurre en la constituciones que establecen la democracia directa. Allí, la legislación corresponde directamente a la asamblea popular. Si ésta no puede reunirse, actúa en su nombre (por vía excepcional) un collegium elegido por ella. De sus resoluciones puede decirse que valen como si fueran adoptadas por el pueblo (o mejor, por la asamblea popular), en el mismo sentido en que se dice que la voluntad del tutor vale como voluntad del pupilo. Esa legislación es el fruto de una especie de mandato imperativo; la entidad de que procede es un órgano del pueblo o de la asamblea popular. Pero, en las constituciones de las democracias «representativas», el pueblo está excluido en principio de la legislación, la cual se encomienda al parlamento elegido por él. Aquí no hay regla positiva que llame al pueblo a legislar; por lo que la competencia legislativa del parlamento no es la excepción, como en el caso anterior. Pero la teoría afirma que el parlamento es un órgano secundario del pueblo, que la voluntad de aquél no es sino la voluntad de éste; ahora bien, esta afirmación no se basa en Derecho positivo, sino en un dogma político: el dogma de la soberanía popular, que afirma que el poder legislativo corresponde «por naturaleza» únicamente al pueblo; por lo cual la atribución al parlamento de la competencia legislativa es una limitación de la regla general. Justamente por esto la teoría de la soberanía popular es una ficción: el dogma político está en contradicción con la realidad política. ${ }^{22}$

Cuando no existe la posibilidad jurídica de que $\mathbf{A}$ realice $\mathbf{X}$, i.e., cuando no se da $\mathbf{M A}(\mathbf{X})$, no puede afirmarse que hay representación. Si se hace la afirmación sobre la existencia de la relación de representación en el caso de que no pueda darse $\mathbf{M A}(\mathbf{X})$, entonces la representación afirmada entre $\mathbf{A}$ y $\mathbf{B}$ es simplemente falsa y constituye una ficción.

Lo anterior es el fundamento para sostener que no existe la relación de representación entre un orden normativo y sus órganos. El Estado no es representado por sus órganos. Hay una organización, no una representación.

La organización (en sentido jurídico-esencial) no es representación, porque ésta es una relación material entre distintos hechos (o entre los hombres que la realizan), mientras que la primera es la relación de un hecho con un orden o sistema de hechos. ${ }^{23}$

${ }^{22}$ Kelsen (TGE. p. 401). Sartori dice: «Una elección, en cuanto tal, no crea un representante. El Papa es elegido por un colegio de cardenales y no es en modo alguno un representante de sus electores». Sartori (TD. T. 1. p. 53)

${ }^{23}$ Kelsen (TGE. p. 400). 
Solamente bajo el supuesto de una personificación del orden jurídico, es decir, únicamente si se considera al Estado como persona capaz de querer es posible comprender la organización, dotar de órganos a un orden, como una relación de representación. Es claro que esta relación no puede darse más que como la aplicación de una ficción, la ficción de la persona jurídica.

\section{La libertad como fundamento conceptual reconstructivo de la democracia y el principio de mayoría: teoría de Hans Kelsen}

Desde la antigüedad clásica, en especial, desde la Grecia del Siglo V a. C., se ha intentado fundamentar conceptualmente a la democracia con base en dos conceptos importantísimos: la libertad y la igualdad. Ambos están estrechamente relacionados, de modo que uno no puede entenderse sin el otro. Sin embargo, es posible enfatizar uno en detrimento del otro, obteniéndose de esta manera dos fundamentaciones posibles de las formas del Estado: con base predominante en el concepto de libertad o con base predominante en el concepto de igualdad.

Nuevamente Kelsen es el autor que con mayor precisión enfrenta el problema, aportando un conjunto de ideas con las que pretende esclarecer, en verdad, la problemática en torno al principio mayoritario.

Para Kelsen, la fundamentación conceptual de la democracia se encuentra en el concepto de la libertad, entendido en su dimensión política.

La idea o ideal que ha servido desde antiguo para clasificar las formas estatales, es la libertad. Es el contrapunto de toda especulación social, a pesar de que lo social es, por naturaleza, unión y vinculación y, en consecuencia, negación de la libertad. La naturaleza se rebela contra la sociedad, contra la coacción consiguiente a todo orden social, contra el tormento de la heteronomía y pide libertad. La carga de la voluntad ajena, impuesta por el orden social, se hace tanto más insoportable cuanto de modo más inmediato se manifiesta en el hombre el sentimiento primario de su propio valor, cuanto más elemental es el impulso que mueve al súbdito contra el que le manda: si es un hombre como yo, yo soy su igual: ¿dónde está su Derecho a mandarme? De este modo, la idea negativa de la igualdad se pone al servicio de la idea, igualmente negativa, de la libertad. ${ }^{24}$

${ }^{24}$ Kelsen (TGE. p. 409). Entre los griegos, en la época clásica de Atenas, los conceptos de libertad e igualdad constituían el fundamento de su orden político y social. La dignidad y la confianza que los atenienses mostraban en sus tratos privados y en sus relaciones internacionales, derivaban de la conciencia que tenían de su propio valer y del hecho fundamental de que los ciudadanos se consideraban a sí mismos como sujetos que gozaban de libertad. En la Oración Fúnebre de Pericles, tal como la reconstruyó Tucídides, podemos leer: «En nuestras relaciones con el Estado vivimos como ciudadanos libres y, del mismo modo, en lo tocante a las mutuas sospechas propias del trato cotidiano, nosotros no sentimos irritación contra nuestro vecino si hace algo que le gusta y no le dirigimos miradas de reproche, que no suponen un perjuicio, pero resultan dolorosas». (Tucídides, II, 37-2) Platón, un enemigo declarado de la democracia, en la República dice que en la democracia la ciudad esta llena de eleutheria (libertad) y libertad de palabra y a cada cual le está permitido hacer lo que le plazca...y cada hom- 
Esta idea negativa de la libertad, como ausencia de todo vínculo social y de toda heteronomía, se convierte, mediante un cambio de significado, en el fundamento del orden social y, en especial, del estatal. Se intenta fundamentar la heteronomía con base en el principio que originalmente se le contrapone. La libertad puramente negativa tiene que operar dentro del ámbito social, por lo que tiene que llevar a cabo una función que originalmente, no sólo le era ajena, sino contrapuesta.

Ahora bien, si ésta (la libertad) se resuelve en un cálculo de lo social (incluso lo estatal) por ella negado, débese a un cambio de significado; la libertad deja de ser negación de lo social (y, en particular del Estado) y se convierte en una forma específica que representa, en unión de su antítesis dialéctica, todas las formas posibles de Estado y Sociedad, democracia y autocracia. ${ }^{25}$

Se trata de hacer compatible el concepto de la libertad con el concepto de lo social, lo cual es una empresa casi imposible de lograr, pues se trata

bre puede planear su vida como quiera. (Rep. 557b) Aristóteles dice: «El fundamento básico del sistema democrático es la libertad (pues esto suelen decir, en la idea de que sólo en este régimen se participa de la libertad, pues éste es, como dicen, el objetivo al que tiende la democracia) Una característica de la libertad es gobernar y ser gobernado por turno... Otra característica es vivir como se quiere; pues dicen que esto es obra de la libertad, si precisamente es propio del esclavo vivir como no quiere». (Pol. 1317b) Morgens H. Hansen ha encontrado siete usos del nombre eleutheria y del adjetivo eleutheros en las fuentes clásicas que describen a la Atenas democrática:

1. Eleutheros es usado de la manera más común como opuesto a esclavo, concordando con Aristóteles.

2. Eleutheria es invocada frecuentemente como un ideal democrático para contrastarla con la tiranía. Hay una invasión de este sentido con el anterior, pues se ha considerado que vivir bajo una tiranía es vivir como esclavo.

3. Eleutheros es un adjetivo que se usa para referirse a los ciudadanos, que han nacido libres en Atenas.

4. También se ha usado para indicar el hecho de participar en las instituciones democráticas, no sólo en la Asamblea, sino poder ser electo en las magistraturas.

5. El ideal democrático de la libertad exige que todos tienen el Derecho de vivir como les plazca, sin ser oprimidos por otras personas o por las autoridades,

6. «Next, eleutheros is often used in the sense of authonomos as against being dominated by others».

7. También es usado el adjetivo para referirse al autocontrol, a la propia mesura. Hansen. (AAML pp. 93-94)

Como puede verse, el concepto de libertad está en contraposición con el concepto de dominio de otro, de sometimiento a la voluntad ajena, tanto en el ámbito público como en el privado. Por tanto, la libertad se encuentra, como concepto, enlazada al concepto del poder del dominio. Es en este sentido clásico que debe comprenderse el concepto de la democracia, como una forma de organización del poder y comprenderla desde este punto de vista. Esto nos conduce a establecer un concepto puramente descriptivo de ella, haciendo a un lado toda concepción que no sea una elaboración del poder y de su contraposición. Los procesos democráticos son procesos de poder, de dominio, de creación de normas obligatorias y coactivas para los súbditos.)

${ }_{25}$ Kelsen (TGE. pp. 409-10). 
de conjuntar en una unidad conceptos que en su origen son contradictorios y, por tanto, incompatibles. Sin embargo, en el caso de que se establezca esta compatibilidad entre la libertad y lo social, que es por esencia la negación de aquélla, entonces se puede convertir en el fundamento de todas las formas fundamentales de la Sociedad y el Estado. La libertad natural se convierte en libertad social y política. ¿Cómo se consigue esto?

Si la Sociedad y el Estado han de existir, precisa también que exista un orden obligatorio para la conducta recíproca de los hombres y, por consiguiente, una autoridad. Pero ya que hayamos de ser gobernados, aspiramos al menos a gobernarnos por nosotros mismos. Así, la libertad natural se convierte en libertad social o política. Es políticamente libre quien, aun estando sometido, lo está solamente a su propia voluntad y no a la ajena. Con esto queda planteada la principal diferencia entre las formas de Estado y de la Sociedad. ${ }^{26}$

Esta es la transformación que sufre el concepto de libertad para convertirse en el fundamento de nuestras ideas de la democracia. Quizá el teórico más consecuente es Rousseau, quien no duda en sacar las conclusiones de su planteamiento fundamental, todo lo cual queda expresado en el siguiente párrafo de Kelsen:

Rousseau, tal vez el primer teórico de la democracia, plantea la cuestión relativa al Estado ideal, que es para él el problema de la democracia, en estos términos: «¿Cómo podría encontrarse una forma de sociedad que defienda y proteja a cada uno de sus miembros, y en la cual cada uno, aun uniéndose a los demás, sólo se obedezca a sí mismo y mantenga, por consiguiente, su libertad anterior?» La gran importancia que para él tiene la libertad como base y eje de su sistema político, está manifestada por sus críticas contra el principio parlamentario en Inglaterra. «El pueblo inglés se cree libre, pero se engaña extraordinariamente, pues lo es sólo al elegir a sus diputados; una vez elegidos, vuelve a la servidumbre y queda anulado». Rousseau, como es sabido, deduce esta consecuencia de lo indirecto de la democracia. Aun cuando la voluntad imperante en el Estado se ha constituido por decisión inmediata del pueblo, el individuo sólo ha resultado libre en un momento: el de la votación, y esto suponiendo que haya votado con la mayoría y no con la minoría derrotada. ${ }^{27}$

Esta es la consecuencia lógica de la aceptación del principio de la libertad como fundamento de la democracia. Este mismo principio debería operar congruentemente en todo momento de la existencia del Estado, pues se desea conservar la libertad siempre en todo régimen. Pero esto no es posible y debe abandonarse el postulado de la libertad si se quiere explicar la validez y existencia objetiva del Estado y del orden jurídico. Este no podría existir si se requiriera la voluntad constante y perpetua de los sujetos sometidos al mismo y, además, con el principio de la unanimidad.

\footnotetext{
${ }^{26}$ Kelsen (EVD. pp. 16-7).

${ }^{27}$ Kelsen (EVD. pp. 18-19; FD. p. 234 y ss).
} 
Ahora bien, dada la comprobada diversidad de los intereses, (la unanimidad) es esto tan difícil en la vida práctica del Estado, que incluso un apóstol de la libertad, como lo era Rousseau, sólo exigía la unanimidad para el contrato social constitutivo del Estado. Esta restricción del principio de la unanimidad al acto hipotético de la creación del Estado no se explica solamente por razones de oportunidad, como suele suponerse. Del principio de la unanimidad, derivado de la aspiración hacia la libertad, para la celebración del contrato social, resultaría en rigor que también el mantenimiento de éste dependería del asentimiento constante de todos, y, por consiguiente, que todos estarían autorizados para separarse de la comunidad y sustraerse a la vigencia del orden social mediante la negación de éste. En ello se manifiesta claramente el conflicto insoluble entre la idea de la libertad individual y la de un orden social, el cual en su esencia íntima sólo es posible en un régimen que, al fin y al cabo, no depende de la voluntad de los sujetos a él. ${ }^{28}$

El orden social debe mantenerse. Entonces, el principio de unanimidad debe ser sustituido por el de mayoría. ${ }^{29}$ Esto no es satisfactorio, conforme al planteamiento inicial, pues la minoría no resultaría obligada por la norma creada por la mayoría, dado que no ha otorgado su consentimiento a ello. Ahora bien, urge preguntarse ¿cómo puede justificarse el principio de mayoría absoluta con base en el concepto de libertad? Kelsen intenta la fundamentación de tal principio con un razonamiento muy ingenioso: no se respeta el principio de libertad cuando se acepta la mayoría absoluta, pues por lo menos el $49 \%$ de la población no está de acuerdo con la norma o conjunto de normas aprobado, pues han votado en contra. Estos sujetos que forman el $49 \%$ no son libres en el sentido que hemos explicitado. Entonces, entran en operación otras reflexiones, que hacen plausible el principio de mayoría. Partamos de los supuestos siguientes: 1. todos los votos valen igual (principio de igualdad) y 2. existe por necesidad una minoría. Si se exigiera normativamente la unanimidad, tendría que afirmarse que lo que existe es una tiranía o despotismo, si se quiere de carácter negativo, del disidente. Basta que uno no quiera, que se oponga, que diga «no», para que todos los demás, $99 \%$, no puedan realizar o llevar a cabo su voluntad. El único «libre» sería el disidente, pues su voluntad es coincidente con la voluntad estatal: no se ha creado un $\mathbf{O N}$ con un cierto contenido, contenido que los demás sí quieren, excepto él. La exigencia de la unanimidad destruye totalmente la democracia y crea su antípoda: la tiranía o el despotismo. Si todos votan favorablemente, todos son libres. Basta que uno vote en contra, para que sólo ese sea libre y todos los demás estarán sometidos a la voluntad del disidente.

Pensemos ahora en la situación que se presenta en el caso de que se exija una mayoría calificada del $75 \%$. La minoría es 25 . Para que esta minoría

\footnotetext{
${ }^{28}$ Kelsen (EVD. p. 20).

${ }^{29}$ Cf. Kelsen (FD. pp. 235-7).
} 
sea libre, para que haya coincidencia entre su voluntad y la norma estatal, necesitan realizar una actividad prodigiosamente intensa, pues esos 25 deberán convencer a 50, para convertirse en mayoría y lograr la coincidencia de voluntades individuales y estatal. Tanto más difícil es esto, si se considera que a los 50 que tienen que convencer han formado una mayoría opuesta a sus voluntades. Cada uno de los 25 debe convencer a 2 de los contrarios.

Con la mayoría absoluta encontramos una situación completamente distinta: la minoría de 49 sólo tiene que convencer a 2 de la mayoría, para convertirse a su vez en mayoría, lo cual es fácil y probable de conseguir. Por lo tanto, la minoría puede fácilmente ser libre, la probabilidad es alta, toda vez que casi siempre es posible encontrar alguna divergencia en las opiniones mayoritarias, que a algunos inclinarían a adoptar las posturas que postula la minoría. Creo que las anteriores explicaciones permiten comprender el siguiente párrafo de Kelsen:

Pero aun quien vota con la mayoría no se somete sólo a su propia voluntad. Esto se experimenta cuando se modifica esta voluntad. Tal modificación carece de todo valor jurídico; y entonces surge con toda claridad la «voluntad ajena», la validez del orden a que se está sometido. Para que el individuo fuese de nuevo libre, tendría que encontrar una mayoría que estuviese de acuerdo en cambiar nuevamente su voluntad. Y esta concordancia entre la voluntad individual y la del Estado es tanto más difícil, y tanto menor la garantía de la libertad individual, cuanto más calificada es la mayoría requerida para modificar la voluntad estatal existente. $^{30}$

Con la mayoría absoluta la política tiende a convertirse en una política de compromiso. Esto es cierto, pero debe reconocerse que estas consideraciones ya no son una aplicación estricta del principio de libertad.

\section{La igualdad como fundamento conceptual reconstructivo de la democracia y el principio de mayoría: una métrica del poder para resolver los conflictos.}

Vimos más arriba que el concepto de libertad funciona como el contrapunto de toda especulación social, a la manera como el estado de naturaleza se postula con objeto de poder construir, con el contrato social, el concepto de los social y lo estatal. Estrechamente unido al concepto de libertad, es más, indisolublemente conectado con él, se encuentra el concepto de la igualdad, de manera que uno y otro no pueden ser aplicados a la realidad social separadamente, pues el concepto de la libertad entraña el de la igualdad y viceversa, para la comprensión del orden jurídico democrático. Esto es fácilmente comprensible con sólo hacer la siguiente reflexión: si los

\footnotetext{
${ }^{30}$ Kelsen (TGE. p. 411).
} 
hombres son libres en la medida en que no se encuentran sometidos a la voluntad de ningún otro hombre, entonces son iguales en ese respecto, debido a que no puede predicarse de ningún hombre que se encuentra en una relación de superioridad normativa respecto de cualquier otro. Si todos son libres, entonces son igualmente libres. Y también a la inversa: si todos los hombres son iguales, ninguno se encuentra sometido normativamente a otro hombre y, por lo tanto, son libres. Aunque ambos conceptos se coimplican, con el objeto de fundamentar a la democracia puede enfatizarse uno a costa del otro, obteniéndose con ello una fundamentación diferente

El concepto de la igualdad es rechazado generalmente como fundamento de la democracia y del principio de mayorías que le es característico. Ya hemos visto cómo el principio de las mayorías es deducido o derivado del concepto de libertad política. Kelsen rechaza que pueda derivarse el principio de mayorías del concepto de la igualdad política. Dice:

De esta idea (de la libertad) ha de derivarse el principio de mayorías, y no de la de igualdad, como suele hacerse. Sin duda, el supuesto del principio mayoritario es la igualdad de las voluntades humanas. Pero esta «igualdad» no es más que una imagen, no puede significar el que todas las voluntades y personalidades humanas puedan efectivamente medirse y adicionarse. Sería imposible justificar el principio de mayorías diciendo que muchos votos «pesan más» que pocos. De la presunción puramente negativa de que ninguna voluntad vale más que la otra, no puede seguirse positivamente que deba valer la voluntad de la mayoría. Si el principio mayoritario deriva exclusivamente de la idea de igualdad, tiene un carácter mecánico y falta de sentido, como le reprochan los partidarios de la autocracia. Sería la fórmula decente del hecho brutal de que los más son más fuertes que los menos; y el principio de que el poder precede al Derecho, no quedaría superado sino convirtiéndolo en proposición jurídica. ${ }^{31}$

A pesar de esta opinión, es posible derivar el principio de mayorías del concepto de igualdad política. Es más, la derivación hecha por Kelsen a partir del concepto de la libertad me parece artificial y de ninguna manera convincente. La minoría es muy grande en la votación por mayoría absoluta, por lo que un número considerable, casi igual al de la mayoría, se encuentra en el partido opositor, lo que contradice el principio de que el mayor número de sujetos debe ser libre. El 49\% no es libre en el sistema mayoritario, pues el concepto de libertad en Kelsen tiene un carácter material subjetivista: soy libre si participo en el proceso de formación de la voluntad estatal (ley) y esta tiene un contenido coincidente con el contenido de mi voluntad. Soy libre si hay coincidencia entre mi voluntad y el orden social.

Aunque pueda ser calificada de «chocante» la derivación del principio de mayorías del concepto de la igualdad y se le considere una manifestación

\footnotetext{
${ }^{31}$ Kelsen (TGE. p. 412).
} 
«decente» de un «hecho brutal», creo que es el camino que debe seguirse para comprender a la democracia.

Si contrariamente a lo que acontecía en Grecia y Roma, el mundo moderno postula la autonomía del individuo, entonces el concepto exagerado del propio valor individual reclama y exige que toda resolución social, vinculante para un grupo de personas, sea aprobado por el individuo que se va a encontrar sometido a la decisión correspondiente. Esta idea llevada a sus conclusiones más consecuentes destruye su propia función, pues es incapaz de fundar conceptualmente la existencia del mundo social. Ella presupone que sólo se puede obligar autónomamente a los sujetos, es decir, que la obligación es una restricción autoimpuesta por el propio sujeto a las posibles conductas. El fundamento de la obligación social se encuentra en el consentimiento de los sujetos que van a estar obligados por las decisiones sociales. Lo social se atomiza en la suma de las voluntades individuales y los conjuntos se disuelven en los elementos que lo integran. Si la decisión social es obligatoria para los miembros de la comunidad, entonces, bajo estos supuestos, solamente se actualiza dicha obligación en la medida que se encuentre vinculada a la aquiescencia de los miembros de la misma. Como el fundamento de la obligación está en la propia voluntad, estoy obligado en la medida en que así lo quiero. Si por cualquier eventualidad la voluntad no se inclina ante la exigencia social, ésta pierde o no alcanza a tener esa dimensión restrictiva obligatoria. De esta manera no puede fundarse el orden social y, menos aún, el principio de mayoría. Es el camino que sigue el concepto de la libertad, el que debería conducir al principio de unanimidad que, como se ha demostrado, resulta en el dominio negativo del disidente, en tanto que la mayoría, incluso del $99 \%$, no podría establecer el orden social con un cierto contenido, si hubiera un solo sujeto que no estuviera de acuerdo.

Los conceptos que deben utilizarse para fundamentar la reconstrucción conceptual de la democracia con base en el principio de igualdad, son los siguientes:

1. La igualdad de los participantes en la votación.

2. Determinación de las fuerzas reales en el plano representativo.

3. Una métrica de las fuerzas (del poder) y de la lucha a través del computo de los votos.

4. La anticipación simbólica de los posibles resultados de una lucha real.

5. La finalidad de la votación mayoritaria es evitar la confrontación violenta por medio de la lucha. ${ }^{32}$

${ }^{32}$ Me encontré en la Sociología de Simmel un párrafo que contiene tesis idénticas a las que se consignan en este trabajo, el que vale la pena transcribir por su precisión y exactitud. Debo confesar que acomodé mi terminología a la de Simmel. 


\subsection{La igualdad de los participantes en la votación}

Una observación previa: el principio de igualdad que se presupone en las votaciones democráticas tiene una función específica y única: es el fundamento conceptual necesario para establecer la métrica de las fuerzas y del poder de los diversos grupos o partidos que participan en la democracia. Además, con base en nuestro apego al principio de la neutralidad valorativa, el principio de la igualdad no contiene valoración alguna. Sólo opera dentro del ámbito de la democracia, para hacer posible la medición del poder y de las fuerzas de los grupos o partidos participantes

Desde siempre se ha afirmado que los miembros de un cuerpo colegiado que participan en la toma de decisiones de acuerdo con el principio de la mayoría deben ser considerados, para los efectos de la votación, como iguales, de manera que el voto de cada individuo tenga un valor igual al voto de cualquier otro individuo. Este es un presupuesto imprescindible para el correcto funcionamiento plenamente democrático de una asamblea deliberativa y decisoria. En el caso de que este requisito no se cumpliera, la función de la votación sería impedida y se daría lugar a la predominancia de cualquier miembro de ella al que se le adscribiera mayor valor.

Esta igualdad no es un postulado arbitrario, pues no sería válida la afirmación de que la igualdad presupuesta en la votación es absolutamente ficticia, irreal, pues en la vida diaria de los hombres y en sus relaciones sociales los hombres no son iguales y, es más, no pueden ser iguales. Por ello, se podría afirmar, el procedimiento y la votación mayoritaria es un constructo artificial para favorecer, en términos de la filosofía nietzscheana, de Calicles o de Critias, a los súbditos, a los débiles, para debilitar a los fuertes e imponerse a ellos, utilizando como medios los característicos de esta clase de gentes, la mentira y las ficciones idealizadoras. En verdad, el procedimiento democrático de la votación mayoritaria es una ficción, pero no es una ficción arbitraria, es una idealización, de profundas consecuencias sociales,

«Aunque, o más bien, porque en una votación los individuos valen igual, la mayoría - lo mismo si se trata de votación propia que de votación por representantes - tendría fuerza física suficiente para forzar a la minoría. La votación entonces tiene por finalidad el evitar que se llegue a una efectiva medición de las fuerzas, anticipando en el escrutinio su resultado eventual, para que la minoría pueda convencerse de la ineficacia de una resistencia efectiva. En el grupo total encuéntranse, por tanto, frente a frente, dos partidos, o, por decirlo así, dos sub-grupos, entre los cuales decide la fuerza, medida en este caso por los votos. La votación presta entonces el mismo servicio metódico que las negociaciones diplomáticas, o de otro orden, entre los partidos que quieren evitar la ultima ratio de la lucha. En último término, el individuo, en este caso, no cede (salvando algunas excepciones) sino cuando el adversario le demuestra claramente que si llegara a una lucha perdería, por lo menos, tanto como quiere ganar. La votación, como las negociaciones, proyecta las fuerzas reales y su cómputo en un plano espiritual; es la anticipación simbólica del resultado que habrían de tener la lucha y pugnas concretas». Simmel (S. pp. 190-191). 
demasiado reales para descalificarlas con un simple gesto de desdén. En el próximo apartado se verá cuál es esta función. Lo que importa en este lugar es determinar la validez de la ficción, de la idealización de la igualdad. Como veremos más adelante, la democracia establece una métrica del poder y esta métrica sólo es posible si se consideran unidades del mismo tipo, i.e., iguales.

\subsection{Determinación de las fuerzas reales en el plano representativo}

La democracia es un constructo social, una institución, cuya función principal es la proyección de las fuerzas reales a un plano superior, simbólico de carácter social. Tenemos tres planos: uno real de los acontecimientos, otro de carácter contrafáctico y otro distinto, también real, de carácter simbólico o representativo, que se refiere al primero. Podemos llamarlos, respectivamente plano real, plano contrafáctico y plano representativo. $\mathrm{El}$ primero está constituido por una serie de acontecimientos reales, que se ha construido en el curso de la historia de un hombre o de un pueblo y que consiste en los intereses y los conflictos reales que existen en el grupo social. El plano representativo tiene una referencia al plano real: se refiere a él, en el sentido de que está por él, lo sustituye. El plano contrafáctico sería aquel que se presentaría en el caso de que el plano representativo fallara en el cumplimiento de sus funciones sociales. Esto merece una aclaración breve. ${ }^{33}$ La conceptuación del juego hecha por G. Bateson tiene grandes similitudes con los conceptos que se expondrán a continuación.

\footnotetext{
${ }^{33}$ Hay un concepto muy interesante que introduce Goffman en FA para la comprensión de la conducta humana: es el de «llave» o «clave» (Key). Para introducirlo señala algunas observaciones de G. Bateson sobre el juego de los animales. Las acciones que conforman al juego están realizadas mediante la aplicación de una transformación especial a la que llama «clave» o que podríamos llamar «código». Las acciones del juego son el resultado de una «codificación», de una transformación de la conducta original a la cual se refieren.

«Rather, this play activity is closely patterned after something that already has a meaning in its own terms -in this case fighting, a well-known type of guided doing. Real fighting here serves as a model, a detailed pattern to follow, a foundation for form. Just as obviously, the pattern for fighting is not followed fully, but rather is systematically altered in certain respects. Bitinglike behavior occurs, but no one is seriously bitten. In brief, there is a transcription or transposition -a transformation in the geometrical, not the Chomskyan, sense- of a strip of fighting behavior into a strip of play». (p. 41)

Lo que importa destacar de estas observaciones de Goffman, obtenidas de Bateson, son varios hechos, entre muchos otros que pueden obtenerse:

a. Hay una serie de conductas que no existen aisladas, que no son autónomas, sino que son el producto de una transformación de otra serie de conductas; éstas son el modelo de aquéllas. Podemos llamarlas conductas-modelo y conductas-transformadas.

b. La secuencia de actividades que constituyen las conductas-modelo no son seguidas fielmente ni de manera completa por la serie de conductas-transformadas.

c. La función de las conductas-modelo puede ser distinta e incluso opuesta a la función de las conductas-transformadas.
} 
Lo que puede crear alguna dificultad es la expresión de que el plano representativo se refiere al plano real y al plano contrafáctico. Es más exacto decir que el plano representativo sustituye, o está por estos dos últimos planos. El plano representativo es también real, pero tiene una función distinta: es el plano institucional de la democracia tal como la hemos descrito. El plano real y el contrafáctico se retiran a un trasfondo y sólo aparecen y se manejan dentro del plano representativo. En esto, somos constructivistas. No podemos colocar nuestros pies en el plano real, como si éste estuviera dado. Esta expresión «dado» hay que utilizarla, para rechazar su sentido. Algo ajeno al plano representativo no se puede dar en el ámbito social, pues es precisamente este plano representativo el que constituye o crea la realidad social; la invasión del plano real al plano representativo es algo que no puede ser afirmado. El plano real sólo puede romper y destruir el plano representativo, no actuar dentro de él. El plano representativo sólo se mueve dentro del plano representativo y nunca pasa al plano real, so pena de ya no ser plano representativo. El ciervo europeo sustituye el ataque y la lucha real, en la que ambos contrincantes pueden resultar seriamente lesionados, por una competencia de fuerza consistente en una carrera junto al enemigo,

d. Puede acontecer que las conductas-transformadas tengan como función la exclusión en el mundo real de las conductas-modelo.

e. La regla de transformación puede establecer una métrica específica de las conductasmodelo o de las situaciones en las que éstas se producen.

Hay muchas otras características que pueden encontrarse en los juegos y otras series de conductas-tranformadas, las que no se expondrán en este lugar, por no ser pertinentes para las finalidades del presente ensayo. Hay una clave muy importante para reconocer cuando se concibe un proceso como una serie de conductas-transformadas: es la utilización de metáforas que se utilizan en la descripción de las conductas-modelo.

${ }^{34}$ En el siguiente párrafo de Lorenz puede verse la formación filogenética de un ritual semejante en el que encontramos la misma proyección de la que habl;amos en el texto de este ensayo: «Otra forma de amenaza se formó en muchos teleósteos y peces del género perca a partir de una embestida de frente frenada por el miedo. Los dos peces enfrentados se acercan lentamente el uno al otro, con el cuerpo preparado en forma de S, y enroscado como un resorte, listos para atacar. Por lo general abren al mismo tiempo los opérculos de las branquias o hinchan la membrana de éstas, lo cual corresponde al despliegue de las aletas en la amenaza de flanco, ya que también hace aparecer ante al adversario una gran corpulencia. Durante la amenaza frontal, sucede a veces que muchos peces tratan al mismo tiempo de apresar entre sus dientes la boca que les presenta el adversario; y de acuerdo con la situación conflictiva qque da origen a la amenaza frontal, no se atacan decidida y furiosamente, en embestida o como lanzándose al abordaje, sino que siempre el encuentro es tímido y cohibido. Esta «lucha con la boca», se ha transformado en algunas familias, como la de los peces laberinto, que son parientes lejanos de las percas, y en los cíclidos, que son sus mejores prototipos, en pautas agonísticas ritualizadas en extremo interesantes. En ellas los rivales «miden» literalmente sus fuerzas sin hacerse daño. Estos campeones tienen las mandíbulas protegidas por una gruesa capa de cuero, difícil de atravesar, y tiran con todas sus fuerzas cada quien de las mandíbulas del otro. Así se desarrolla un forcejeo muy parecido al Hosenwrangeln, deporte de los antiguos 
hasta el momento que uno de los beligerantes, por cansancio, desiste. ${ }^{34} \mathrm{El}$ ciervo europeo cuando corre y camina con el ciervo con el que está en estado de beligerancia actúa en el plano representativo, toda vez que la carrera es la conducta recíproca que está por el combate real, lo sustituye. Si en un momento determinado, el ciervo deja de correr y empieza a atacar con los cuernos a su contrincante, el plano representativo ha sido destruido, hecho a un lado y se ha caído en el ataque inmisericorde: se ha colapsado el plano contrafáctico en el plano real, lo que quiere decir, que la situación de conflicto ha llegado a tal extremo de tensión que en vez de operar en el plano representativo se está actuando en el plano en el que se ha colapsado el plano contrafáctico. Esto quiere decir, que el conflicto ha desembocado en un combate real, que era el que se intenta evitar operando en el plano representativo. Ya no hay función representativa, sólo conductas reales.

La determinación de las fuerzas operantes en el plano real hecha en el plano representativo es una correspondencia específica de los dos planos mencionados. No hay adecuación alguna a una realidad dada, sino cuando mucho un cierto isomorfismo entre el plano representativo y los planos real y contrafáctico, creados como referencias del plano representativo. Éste no es idéntico al plano real, menos al contrafáctico; los construye. Una vez que se ha creado el plano representativo debe seguir operándose dentro de él y las consecuencias o configuraciones que se obtengan en él, serán consideradas por los sujetos involucrados como consecuencias que podrían producirse en caso de que se colapsara el plano contrafáctico en el plano real. Se maneja la realidad dentro del ámbito del plano representativo y hay un ir y venir, más o menos isomorfo, entre ambos planos. Ejemplo: una votación popular se encuentra en el plano representativo y construye una mayoría so-

campesinos suizos, que podían durar horas enteras jalándose de los pantalones cuando ambos justadores eran de fuerza igual. Y entre los cíclidos Aequidens latifrons, de un hermoso color azul, una vez registramos un forcejeo de este tipo, entre dos individuos de fuerza bastante igual, que duró desde las ocho y media de la mañana hasta las dos y media de la tarde.

Este «jaloneo de boca», que en algunas especies es más bien «estrujamiento», porque los peces se empujan en lugar de tirar uno del otro, procede, a mayor o menor distancia en el tiempo según la especie, del primitivo combate en serio. Entonces los peces se tratan sin ninguna inhibición e intentan penetrar en el flnaco no protegido del adversario y herirle lo más profundamente que puedan. El ceremonial del duelo ritualizado, de la amenaza sin hacerse daño, seguido por el forcejeo destinado a medir las fuerzas era, pues, primitivamente el preludio al combate asesino destinado a hacer daño. Pero un preludio tan minucioso tiene un papel extraordinariamente importante que desempeñar, puesto que proporciona al rival poco fuerte la ocasión de dejar la palestra si ve a tiempo que no tiene esperanzas de triunfar. De este modo se realiza la función (conservadora de la especie) del encuentro entre dos rivales, que es la selección del más fuerte, sin necesidad de que haya ningún muerto, ni siquiera heridos. Solamente en el caso de que los dos campeones sean de fuerza exactamente igual ha de lograrse la decisión derramando sangre.» Lorenz (SLA. pp. 127-8). 
cial, una fuerza social, respecto de la cual no existe realidad dada con la cual contrastarla. La votación crea la fuerza social correspondiente. No sabemos si uno de los ciervos beligerantes va a ganar en una pelea real, pero en el plano representativo ritual se ha constituido o creado al vencedor, como el más fuerte.

\subsection{Una métrica de las fuerzas (del poder) y de la lucha a través del cómputo de los votos}

El plano representativo está estructurado de tal manera que se ha establecido una métrica de la lucha y de las fuerzas que operan en el plano real de la vida social. Es cierto, se pueden contar los elementos importantes en el plano real que pudieran tener significación en el caso de un combate concreto; en el caso de los ciervos, el número posible de golpes asestados al enemigo con sus cuernos, la magnitud probable de las heridas inferidas y la gravedad de las mismas por el daño a los tejidos involucrados. Esto no podría establecerlo el ciervo, pero en el plano representativo tiene un elemento que puede experimentar con toda claridad, que indirectamente representa el resultado posible de la lucha. Si por cansancio deja de correr, mientras que el ciervo contrincante continúa la carrera, ese es un signo socialmente constituido de la mayor potencia del contrincante. El plano representativo establece una métrica específica de ciertos elementos relevantes del plano real: en la lucha, la capacidad de inferir heridas o la muerte, es decir, el poder de imponer la propia voluntad al adversario por medio del uso de la violencia física.

En el ámbito social humano, como los bienes son escasos y los conflictos son interminables, la democracia con sus procedimientos de votación ha establecido una métrica de la relativa fuerza o poder de los partidos en pugna. La pluralidad de intereses y posiciones sobre temas de importancia para el grupo social, que con facilidad puede conducir a los conflictos armados y a la lucha real y concreta, con sus consecuentes peligros e inconveniencias, hace necesario que se establezca un procedimiento que determine y construya socialmente la fuerza de cada uno de los partidos en pugna, bajo el supuesto que todos los participantes sean iguales, pues de lo contrario la métrica no es posible conceptualmente. Con ello, existe a disposición del grupo social un método específico, manejable al arbitrio de los participantes, para determinar cuál de los grupos o partidos en pugna saldría vencedor en el supuesto contrafáctico de que se llevara a cabo la lucha por la realización de los intereses que cada grupo o partido propugna. Es un método para determinar el grado de poder que cada partido en pugna pudiera ejercer. La votación mayoritaria favorable a un partido determina que es más fuerte, que tiene más poder y que, por lo tanto, momentáneamente pue- 
de imponer su voluntad, en forma de emisión de normas, en general, y leyes, en particular, a la totalidad del grupo que domina. Este es el sentido del principio de mayorías: proporciona el criterio y una métrica del poder.

\subsection{La anticipación simbólica de los posibles resultados de una lucha real}

En los asuntos humanos, se ha encontrado una métrica determinada, bajo el supuesto de la igualdad de los participantes en la contienda: se cuenta el número de votos $\mathrm{y}$, con ello, se determina la fuerza del contrincante y el posible resultado de una lucha podría desencadenarse por el conflicto. Más votos son, aunque parezca una verdad de perogrullo, una cantidad mayor de votos. La regla de tener por aprobado una decisión determinada con un contenido específico por haberse alcanzado la mayoría, es la representación, en el plano representativo, de la situación que prevalecería en el caso de un conflicto real cuyo resultado sería el contenido de la decisión realizado en el plano real. La operancia de los elementos en el plano representativo y las configuraciones que se obtengan dentro de él, reflejan en el éste plano lo que podría acontecer en el plano real en el caso que la acción ahí se verificara. El plano representativo se refiere al plano contrafáctico: si las cosas se llevaran al plano real, lo que no es cierto, acontecería en él, exactamente lo correspondiente a lo que ha acontecido con los elementos del plano representativo. Las configuraciones que se obtienen o se construyen en el plano representativo se refieren a los elementos respectivos en el plano real, el cual tendría la misma configuración de elementos dentro de él, que el que tienen los del plano representativo.

\subsection{La finalidad de la votación mayoritaria es la evitación de la confrontación violenta por medio de la lucha}

El plano representativo funciona a la manera de un mapa: sustituye al plano real, se refiere a él y contiene los elementos necesarios para identificar sus características relevantes y que interesan políticamente. La operancia en el plano real es sumamente peligrosa, máxime tratándose de conflictos y luchas. En vez de enterrarse los cuernos en la carne, que puede llevar a la muerte, se puede operar en el plano representativo y anticipar lo que probablemente acontecería en el plano real en caso de que se colapsara el plano contrafáctico en el plano real.

Cuando el matemático establece las funciones que operan entre ciertas magnitudes, es capaz de determinar cuáles serán las magnitudes que se obtendrían en el caso de que una de ellas variara. El matemático sólo opera en el plano de la matemática y no en el plano de la realidad. Sin embargo, existe un isomorfismo entre sus operaciones y los desarrollos de los sucesos a 
los que se refieren las magnitudes. Los resultados que se obtienen de resolver sus ecuaciones diferenciales se encuentran relacionados a los sucesos a los que se refieren esas magnitudes, ya sean posiciones, momentos temporales, trechos, volúmenes y cualquier elemento que tenga una magnitud intensiva. No puede decirse que el plano representativo reproduzca con exactitud las operaciones y relaciones entre los elementos en el plano real o del contrafáctico, pero si permite obtener magnitudes que se refieren a circunstancias externas como resultado del proceso. Es claro que las argumentaciones no son golpes y que los votos no son balazos, pero la mayoría indica con estas palabras el posible triunfo en una contienda de los partidos que han sido representados en las Cámaras. La finalidad de todo esto, es evitar la guerra, el combate, la lucha, con todos los costos que esto implica.

El plano representativo es un modelo posible del plano contrafáctico considerado contrafácticamente, un modelo que reduce la complejidad de éste, puesto que sólo opera con algunos elementos que se han determinado como importantes del plano real. Ha decidido operar con un conjunto limitado de elementos que se encuentran en el plano real de referencia y a esos elementos les ha dado existencia y dimensión dentro del plano representativo con sus propios medios y sus propias reglas de operación.

La democracia supone la construcción de un modelo minúsculo de la sociedad en su conjunto y la sustitución de las guerras y las luchas en ésta por la argumentación y la oposición argumentativa en aquélla. ${ }^{35}$

Cuando en el plano representativo se ha obtenido una mayoría de votos, ya sea en las elecciones o en el proceso parlamentario, esto significa que se ha hecho una medición de las fuerzas respectivas de los partidos y se ha considerado aceptar la imposición, si se quiere transitoria, de la posición política sustentada por el partido mayoritario. Es el signo de lo que acontecería en el caso de que el plano contrafáctico se llevara a la realidad: si se realizara una lucha violenta.

Dice Clausewitz, el clásico autor sobre la guerra:

Vemos, por lo tanto, que la guerra no es simplemente un acto político, sino un verdadero instrumento político, una continuación de la actividad política, una realización de la misma por otros medios. ${ }^{36}$

${ }^{35}$ Nuestro lenguaje, que refleja una concepción social válida, lo refleja en la metáfora «LA ARGUMENTACIÓN ES UNA GUERRA». Lakoff y Johnson, en MVC, presentan esta metáfora con estos ejemplos: Tus afirmaciones son indefendibles / Atacó todos los puntos débiles de mi argumento / Sus críticas dieron justo en el blanco / Destruí su argumento / Nunca le he vencido en una discusión / ¿No estás de acuerdo? Vale, ¡dispara! / Si usas esa estrategia, te aniquilará.

${ }^{36}$ Clausewitz (G. p. 24). 
Esto es relativamente cierto. Pero quizá debiéramos invertir el concepto, para establecer una equivalencia: la actividad política es una continuación de la guerra, una realización de la misma por otros medios. ${ }^{37}$

Si esto es cierto, entonces, podemos establecer una relación de equivalencia entre la guerra y la política, de manera que donde existe una guerra encontramos a la política y toda política se explica por la guerra que entraña. Esto ya lo había visto Weber. Todo poder -y la política es ejercicio de obtener y mantener el poder o el dominio- genera beligerancia, oposición y es, por tanto, una guerra entre el poderoso y los sometidos o dominados. ${ }^{38}$ El poderoso establece cargas a los dominados, los obliga, los condiciona a ciertas conducta que espontáneamente no realizarían y, por ello, existe en éstos la tendencia a desobedecer, a desconocer al poderoso, a incumplir, a decir «no». Sólo que la política no utiliza con exclusividad el medio de la violencia, sino sólo en último extremo, cuando se rompe el ritual político e institucional de la democracia.

El dominado es el adversario, el que pugna contra el dominante, el enemigo, que es una de las caras del concepto dual definitorio de la política, según Carl Schmitt. ${ }^{39}$ Por ello, hay una gran sabiduría en la democracia: es el único sistema de gobierno que en su interior, inmanentemente, en la operancia de sus propios mecanismos, crea su propia unidad y, además, crea su grupo opositor, sin que destruya a éste, sino que lo conserva y lo protege.

La democracia es el único sistema de gobierno que incorpora dentro de sí, de manera sistemática, al grupo externo y enemigo, de modo que dentro del grupo puede ser dirigida la agresión, ritualizadamente, contra el enemigo. La democracia es el único sistema de gobierno en el que se permite la redireccionalidad de la agresión como método de gobierno, en virtud de que

${ }^{37}$ En Sartori (TD. T. 1. p. 65) he encontrado esta misma formulación cuando establece la distinción que denomina «fundamental» entre una visión beligerante y una visión legalista de la política. «En la primera, la fuerza predomina sobre la persuasión, el poder establece el derecho y se intenta resolver los confluictos en términos de derrota del enemigo...En la última, la fuerza se reserva como ultima ratio, como la peor y última razón». Tiene razón cuando observa la inversión que he puesto en el texto de la fórmula de Clausewitz y cuando comenta que «La política es como la guerra - una guerra sin las armas de la guerra, ya que su experiencia central es la hostilidad, la percepción del vecino como un enemigo o, en cualquier caso, como un peligro o una amenaza». Si tomamos en serio la inversión de la fórmula de Clausewitz debemos afirmar que toda política es beligerante, si es democrática. El «estado de naturaleza» de Hobbes es consubstancial a la sociedad. Es el énfasis de lo insociable en el hombre en el famoso aforismo kantiano de la «sociable insociabilidad» del hombre. No hay sociedad sin conflictos, por lo que la distinción de Sartori no se sostiene: la razón legalista es beligerante por otros medios, pues en la democracia la guerra está institucionalizada. La guerra no está institucionalizada en todos los Estados que no son democráticos.

38 Weber (ES. p. 31)

${ }_{39}$ Schmitt (CP. p. 56). 
se han proyectado en el plano simbólico los conflictos y en este plano se resuelven y se abreacciona la agresividad. ${ }^{40}$ En la autocracia simplemente se da la dominación del mamífero dominante, mientras que los demás miembros del grupo sólo les queda obedecer o rebelarse.

\section{La pluralidad de órdenes normativos}

Un supuesto fundamental de las ideas expuestas es que existen muchos órdenes normativos que compiten entre sí, que son efectivos y que de hecho regulan la conducta humana. Quien niegue estos hechos es porque no quiere ver la realidad. Dice Weber:

Las distintas éticas religiosas se han acomodado de diferente modo al hecho de que vivimos insertos en ordenaciones vitales distintas entre sí. El politeísmo helénico sacrificaba tanto a Afrodita como a Hera, a Apolo como a Dionisos, y sabía bien que no era raro el conflicto entre estos dioses. ${ }^{41}$

Que el orden es «válido» para un círculo de hombres se manifiesta en el hecho de tener que ocultar su transgresión. Pero prescindiendo de esta caso límite, muy frecuentemente se limita la transgresión del orden a contravenciones parciales más o menos numerosas; o se pretende, con mayor o menor grado de buena fe, presentarla como legítima. O existen de hecho unas junto a otras distintas concepciones del sentido del orden, siendo en este caso para la sociología todas igualmente válidas en la extensión en que determinan la conducta real. Para la sociología no presenta ninguna dificultad el reconocimiento de que distintos órdenes contradictorios entre sí pueden «valer» unos al lado de otros dentro de un mismo círculo de hombres. Es más, el mismo individuo puede orientar su

${ }^{40}$ Sartori observa: «Ahora insistiré en que la democracia tampoco es pura y simplemente el gobierno de la mayoría. A decir verdad, «el gobierno de la mayoría» es sólo una fórmula abreviada del gobierno de la mayoría limitada, que respeta los derechos de la minoría». Sartori (TD. T. 1. p. 55) Guglielmo Ferrero expresó enfáticamente lo mismo al decir: «En las democracias, la oposición es un órgano de la soberanía popular tan vital como el gobierno. Suprimir la oposición es suprimir la soberanía del pueblo. (Ibídem) La justificación de esto proporcionada por Sartori no es satisfactoria. Sartori (TD. p. 57). Es cierto que el concepto de «pueblo»no puede quedar reducido a la mayoría: el pueblo no es sólo la mayoría. Debe incluir a la minoría. Cuando se traduce pueblo por un criterio mayoritario, dice Sartori, se convierte a la minoría en no-pueblo., en una parte excluida. Esto es correcto si por pueblo sólo se entendiera el conjunto de sujetos que participan en el priceso de formación de las decisiones estatales. En realidad, no es un problema de definición. El puebo tanto participa en la formación de la norma general obligatoria, como es el conjunto de sujetos sometidos a las normas jurídicas obligatorias. La minoría no determina el contenido de la norma obligatoria, pero participa en su proceso de creación: la opinión de la minoría no es coincidente con el contenido de la norma, pero ha participado en el proceso de su formación. Suprimir la minoría es suprimir la democracia, pues se ha destruido y hecho a un lado la métrica para determinar el poder de los grupos en conflicto y aceptar transitoriamente el grupo que tiene más poder. El diálogo es la expresión de la vitalidad de los intereses que participan en la formación de la voluntad estatal. Sin minoría no hay democracia porque se ha eliminado de la vida social y estatal la institucionalización del manejo pacífico de los conflictos.

${ }^{41}$ Weber (PV. p. 168). 
conducta en diversos órdenes contradictorios; y no sólo de un modo sucesivo, cosa de todos los días, sino aun en una misma acción. Quien se bate en duelo orienta su conducta por el código del honor, pero, tanto si oculta esta acción como si se presenta ante los tribunales, orienta la misma conducta por el código penal. Cuando la elusión o la transgresión del sentido (como por término medio es entendido) de un orden se convierte en regla, entonces la validez de ese orden es muy limitada o ha dejado de subsistir en definitiva. Entre la validez y la novalidez de un orden no hay para la sociología, como existe, en razón de sus fines, para la jurisprudencia, una alternativa absoluta. Existen más bien transiciones fluidas entre ambos casos y pueden valer -como se ha indicado- uno al lado de otro órdenes contradictorios, en la amplitud en que alcance la probabilidad efectiva de una orientación real de la conducta por ellos. ${ }^{42}$

No sólo para la sociología es posible la existencia de órdenes normativos válidos para un mismo círculo de hombres que sean contradictorios, sino también para la jurisprudencia, lo que no se intentará demostrar en este lugar. ${ }^{43}$

Esta pluralidad de órdenes contradictorios dentro de una sociedad es la que constituye el pluralismo y, como tiene fundamentos ideológicos distintos, el relativismo, que según Kelsen, es la Weltanschauung que fundamenta a la democracia. Ésta evita, mediante la ritualización del proceso democrático, la guerra, la violencia y los costos inimaginables derivados de ella. La función de la ritualización es la obtención de la paz y tiene una función económica prominente.

La ineficacia de un orden normativo es la eficacia de otro orden. Los órdenes normativos existentes dentro de un Estado se encuentran en pugna entre sí, lo que significa que los órganos de cada uno de esos órdenes están encargados de hacer ineficaces las normas que integran los otros órdenes normativos. Es posible observar y de hecho existe una tendencia integradora de la unidad, lo que es una forma particular de expresar el hecho de que unos hombres intentan, con su conducta, imponer su voluntad a otros hombres, de dominarlos y vencer su posible resistencia. Al final, todo esto se traduce en mandatos que son ejecutados por un conjunto de hombres e inejecutados por otro conjunto, que crean órdenes parciales que se individualizan de manera relativa. Con ello, el concepto de la lucha obtiene su lugar dentro de la teoría jurídica, como ya lo ha tenido en la teoría sociológica.

Debe entenderse que una relación social es de lucha cuando la acción se orienta por el propósito de imponer la propia voluntad contra la resistencia de la otra u otras partes. Se denominan «pacíficos» aquellos medios de lucha en donde no hay una violencia física efectiva. La lucha «pacífica» llámase «competen-

\footnotetext{
${ }^{42}$ Weber (ES. p. 26).

${ }^{43}$ Cf. Schmill (RPTD. P. 165 y ss).
} 
cia» cuando se trata de la adquisición formalmente pacífica de un poder de disposición propio sobre probabilidades deseadas también por otros. ${ }^{44}$

Toda lucha supone una pluralidad de órdenes. Supone, igualmente, la conducta de aquellos órganos de los órdenes normativos tendientes a invalidar las normas de los órdenes en competencia o en lucha.

Las crisis sociales sólo pueden resolverse democráticamente, si por «solución» entendemos un arreglo institucional que no entrañe el uso de la fuerza física y de la guerra, en virtud de que, como se observó antes, es el único sistema que incorpora en su operancia institucional el conflicto y la lucha, por medios simbólicos. Y esto supone, como ya lo observó Kelsen, el relativismo de los conocimientos y los valores.

Una observación final: en este ensayo no hemos considerado a la democracia como un valor ni su concepto como un criterio justificatorio de cualquier decisión. Es posible que la democracia entendida como valor, no sea otra cosa que el reflejo de la paz (ausencia de violencia física) que genera, con todas las implicaciones que esto tiene.

\section{Bibliografía}

AAML Hansen, Mogens Herman. «The Ancient Athenian and the Modern Liberal view of Liberty as a Democratic Ideal» en Democratia. A Conversation of Democracies, Ancient and Modern. Josiah Ober and Charles Hedrick, Editors. Princeton University Press. 1996.

CA Xenophon. The Constitution of the Athenians en Aristotle and Xenophon on Democracy and Oligarchy, Ed. J. M. Moore. University of California Press. 1975.

CD Schmitt, Carl. El Concepto de lo Político. Alianza Editorial. Madrid. 1999. Trad. Rafael Agapito.

CR Fenichel Pitkin. Hanna. El Concepto de Representación. Centro de Estudios Constitucionales, Madrid. 1985.

CTGE Kelsen, Hans. Compendio de Teoría General del Estado. Editora Nacional. México. 1974. Trad. Luis Recaséns Siches y Justino de Azcárate.

CV Weber, Max, La Ciencia Como Vocación. Alianza Editorial. Madrid. 1967. Trad. Francisco Rubio Llorente.

ES Weber, Max. Economía y Sociedad. Esbozo de Sociología Comprensiva. FCE. México. 1981.

FA Erving Goffman Frame Analysis. An Essay on the Organization of Experience. Harper and Row Publishers. 1974.

FD Kelsen, Hans. Los Fundamentos de la Democracia en «Escritos sobre la Democracia y el Socialismo». Selección y presentación de Juan Ruiz Manero Editorial Debate. Madrid. 1988. Trad. Juan Ruiz Manero.

\footnotetext{
${ }^{44}$ Weber (ES. p. 31).
} 
FED Ihering, Rudolf von. El Fin en el Derecho. Biblioteca Omeba. Buenos Aires. 1960.

G Clausewitz, Karl von. De la Guerra. Ediciones Mar Océano, Buenos Aires. 1960. Trad. R.W. de Setaro.

HP Kelsen, Hans. Problemas Capitales de la Teoría Jurídica del Estado, Desarrollados con Base en la Doctrina de la Proposición Jurídica. Editorial Porrúa, S.A. México. 1987. Trad. Wenceslao Roces. Notas, Revisión y Presentación de Ulises Schmill. Es traducción de Hauptprobleme der Staatsrechtslehre entwickelt aus der Lehre vom Rechtssatz. Tübingen: J. C. B. Mohr (Paul Siebeck). 1923.

L Hobbes, Thomas. Leviatán. Editora Nacional. Madrid. 1983

MEDA Ober, Josiah. Mass and Elite in Democratic Athens. Rethoric, Ideology, and the Power of the People. Princeton University Press. 1989.

MVC Lakoff, Georg y Johnson, Mark. Metáforas de la Vida Cotidiana. Cátedra. Madrid. Trad. Carmen González Marín. 1980.

PDDA Ober, Josiah. Political Dissent in Democratic Athens. Intelectual Critics of Popular Rule. Princeton University Press. 1998.

PV Weber, Max, La Política como Vocación. Alianza editorial. Madrid. 1967. Trad. Francisco Rubio Llorente.

PTL1 Kelsen, Hans. Introduction to the Problems of Legal Theory. Trad. Bonnie Litschewski Paulson and Stanley L. Paulson. Clarendon Press. Oxford. 1992.

PTL2 Kelsen, Hans. Pure Theory of Law. Trad. Max Knight. University of California Press. 1967.

RPTD Schmill, Ulises. Reconstrucción Pragmática de la Teoría del Derecho. Editorial Themis. México. 1997.

S Simmel, Jorge. Sociología. Espasa-Calpe Argentina, S. A. Buenos Aires. 1939. Trad. J. Pérez Bances.

SLA Lorenz, Konrad. Sobre la Agresión: El Pretendido Mal. Siglo XXI Editores S. A. de C. V. 1998. México. Trad. Felix Blanco.

SJS. Kelsen, Hans. Der soziologische und der juristischer Staatsbegriff. Kritische

Untersuchung des Verhältnisses zwischen Staat und Recht.(El Concepto Jurídico y el Concepto Sociológico del Estado. Investigación Crítica de las Relaciones entre el Estado y el Derecho). Tübingen: J. C. B. Mohr (Paul Siebeck), 1922.

TD Sartori, Giovanni. Teoría de la Democracia. Alianza Editorial. México. 1996. Trad. Santiago Sánchez González.

TGE. Kelsen, Hans. Teoría General del Estado. Editorial Labor, S.A. Barcelona. 1934. Trad. Luis Legaz Lacambra de Allgemeine Staatslehre. Enziklopädie der Rechts- und Staatswissenschaften, 23. Band. Berlin: Julius Springer. 1925.

TGEJ Jellinek, Georg. Teoría General del Estado. Compañía Editorial Continental S.A. México. Trad. Fernando de los Ríos Urruti. 1956. 
TPD1 Kelsen, Hans. La Teoría Pura del Derecho. Introducción a la Problemática Científica del Derecho. Editorial Losada, S.A. Buenos Aires. 1946. Trad. Jorge G. Tejerina.

TPD2 Kelsen, Hans. Teoría Pura del Derecho. UNAM. México. 1979. Trad. Roberto J. Vernengo.

VSR Kelsen, Hans. Das Verhältnis von Staat und Recht im Lichte der Erkenntniskritik. Zeitschrift für öffentliches Recht, 2. Band, 1921. 